Military Technical College

Kobry El-Kobbah, Cairo, Egypt

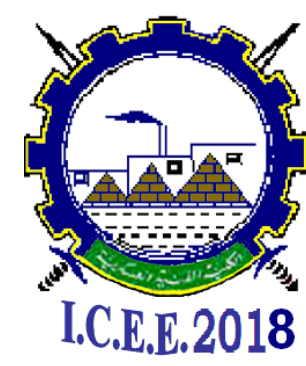

$9^{\text {th }}$ International Conference on

Chemical \& Environmental

Engineering

3-5 April 2018

DFI-2

\title{
Advances in Interfacial Phenomena involving Particle and Surfactants Innovations for Technology Advances
}

\author{
By
}

H. El-Shall ${ }^{1}$, E.A. Abdel-Aal ${ }^{2}$, and A.K. Ismail ${ }^{2}$

\begin{abstract}
Surfaces and interfaces are very important for materials applications in many areas including industrial processes, medical treatments, environmental pollution and remediation, energy production and use, as well as emerging areas in nanoparticles synthesis and utilizations. In this paper, a review of these areas and most recent advances and innovations are discussed. Special emphasis is given to energy generation, medical devices and products, medical applications such as kidney stone formation, dialysis membranes. In addition, minimization of scale formation and inhibition of corrosion in industrial processes and equipment are discussed.

The widespread importance of surfactants in practical applications, and scientific interest in their nature and properties, has precipitated a wealth of published literature. Surfactants form a unique class of chemical compounds. This paper provides an introduction to the nature and physical properties of surfactants, emphasizing their ability to radically alter surface and interfacial properties and to self-associate and solubilize themselves in micelles. These properties provide the means to apply surfactants in wettability modification, detergency, and the displacement of liquid phases through porous media on one hand, and to stabilize dispersions (including foams, froths and emulsions), or to destabilize dispersions (again including foams and emulsions) on the other hand. These in turn lead to a vast array of practical application areas which are illustrated in terms of mineral and petroleum processing, biological systems, health and personal care products, foods, and crop protection.
\end{abstract}

1. University of Florida,

2. Central Metallurgical Research and Development Institute 